\title{
Effect of manual lymph drainage for up to 10 days after total knee arthroplasty: Arandomized controlled trial
}

\author{
Tatsu FuJIURA, MS PT ${ }^{1}$, Hiroshi NAGASAWA, PT, PhD² and Hidetaka WAKABAYASHI, MD, PhD ${ }^{1}$ \\ ${ }^{1)}$ Yokohama City University Medical Center \\ ${ }^{2)}$ Shonan University of Medical Sciences
}

\begin{abstract}
Objective: To assess the effect of manual lymph drainage (MLD) on pain in Japanese patients up to 10 days after a total knee arthroplasty (TKA).

Methods: This study was a randomized controlled trial performed at a University Medical Center. Patients who underwent unilateral TKA and received once daily MLD for 20 minutes prior to standard physical therapy up to 10 days after TKA were investigated. Pain at rest, knee extension muscle contraction, and maximum load were assessed using the visual analog scale $(\mathrm{mm})$ before surgery, after drain removal, and after the fifth MLD. As secondary outcomes, the circumference, range of motion, muscle strength, walking speed, and walking rate were evaluated.

Result: Forty-one patients aged 45-85 participated in this study, 21 of whom were assigned to the intervention (MLD group) and 20 who were not (control group). Ten days after TKA, no significant difference was evident between the MLD and control groups for resting pain [4.5 mm (1.6-10.8) vs $7.0 \mathrm{~mm}(1.8-25.5)$, respectively, $\mathrm{p}=0.17]$, pain during knee extension muscle contraction [12.3 mm (4.5-24.8) vs $20.8 \mathrm{~mm}(6.4-31.8)$, $\mathrm{p}=0.41]$, and pain at maximum load $[13.0 \mathrm{~mm}(8.3-39.8)$ vs $16.0 \mathrm{~mm}(4.6-32.5), p=0.73]$. There were no significant differences between groups in terms of secondary outcomes.

Conclusion: This study shows that MLD up to 10 days after TKA does not affect pain.

Key words: manual lymph drainage (MLD), total knee arthroplasty (TKA), pain
\end{abstract}

(Phys Ther Res 23: 39-46, 2020)

$\mathbf{T}$ used to remove the damaged and deformed surface of a knee joint. Postoperative management of patients is done according to a set hospital schedule starting as early as 1 day after surgery ${ }^{1,2}$. Physical therapy programs are used to advance the recovery of patients within the constraints imposed by strong symptoms of inflammation. Inflammatory processes tend to peak from the seventh to the tenth day post surgery ${ }^{3-6)}$. Control of postoperative pain due to inflammation is an important goal because it facilitates the initiation and maintenance of postoperative physical therapy which can ultimately improve outcomes ${ }^{7,8)}$.

Manual lymph drainage (MLD) has been reported to

Received: May 10, 2019

Accepted: October 23, 2019

Advance Publication by J-STAGE: March 25, 2020

Correspondence to: tatsu fujiura, Yokohama City University Medical Center, 4-57 Urafune, Minami-ku Yokohama, 232-0024, JAPAN

\# e-mail: tatsufujiura@gmail.com

doi: 10.1298/ptr.E9992 reduce acute edema following an ankle sprain and attenuate inflammatory edema resulting from a radial distal fracture in cases of musculoskeletal disease ${ }^{9-13)}$. The effect of MLD on patients after TKA has been reported for two randomized controlled trials. In one study, MLD was performed until the fourth day after surgery. The primary endpoint for this study was range of motion (ROM $)^{14}$. MLD was performed until the seventh day after surgery in the second study and was compared with the use of hypnosis in the placebo group. The primary endpoint was swelling on 7 days and 3 months after TKA. No reduction in postoperative swelling was observed after 7 days or 3 months, and there was no significant difference in reported pain between groups $^{15)}$.

To date, no reports suggest that pain may be the most influential factor affecting a patient's ability after undergoing TKA; instead, the operation itself is typically the primary endpoint. Periods of hospitalization after TKA in Western countries and the United States are shorter than they are in Japan ${ }^{16)}$ and intervention studies do not typically 
evaluate patients until approximately 10 days after surgery, by which time inflammation has reached a peak. Two reports of potential relevance describe Western patients who underwent TKA; however, the mean body mass index (BMI) of those patients was $27.9 \mathrm{~kg} / \mathrm{m}^{2}$ and $29.9 \mathrm{~kg} / \mathrm{m}^{2}$ in the respective studies ${ }^{14,15}$. According to other previous studies, BMIs are vastly different for Japanese patients (24.4 $\mathrm{kg} / \mathrm{m}^{2}$ ) who have undergone TKA ${ }^{17}$.

In this randomized controlled (RCT) study, our aim was to assess the effect of MLD, up to 10 days after TKA, as a postsurgical intervention for acute pain in Japanese patients.

\section{Methods}

\section{Study design}

This study was an open RCT which compared parallel groups. The random allocation ratio between the MLD (intervention) group and the control group was $1: 1$. This trial was registered with the University Hospital Medical Information Network (UMIN), registration number UMIN 000020504. Our research was approved by the Yokohama City University Ethics Committee and complies with the ethical principles of the Declaration of Helsinki. Patients provided their written consent to participate in the study after receiving an oral and written explanation of the purpose of the research.

\section{Inclusion criteria}

Eligible patients were aged between 45 and 85 years and must have undergone a unilateral TKA, regardless of disease state.

\section{Exclusion criteria}

Patients undergoing bilateral TKA or a knee replacement were excluded from this study, as were patients who had a history of deep venous thrombosis or heart failure and whose doctor precluded their participation. Patients were also deemed ineligible if they scored $\leq 23$ points for the Mini Mental State Test (MMSE).

\section{Setting}

This study was conducted at the acute-phase hospital in Yokohama City's University Medical Center where the average length of stay is 12.6 days. Patients were recruited from January, 2016 until May, 2018.

\section{Intervention}

After TKA, MLD was performed on patients for approximately 20 minutes before they received standard physical therapy in the MLD group. MLD was conducted once daily for 5 days, beginning the day following an initial postsurgical evaluation. The control group received standard physical therapy only. The MLD was performed in ac- cordance with the Földi method ${ }^{18-20)}$ by a qualified and experienced MLD therapy practitioner who had received 135 hours of theoretical and practical MLD training. Affected limbs were prepared by the provision of gentle massage prior to the patients performing shoulder joint rotation and diaphragmatic breathing (ie, 10 deep breaths) in the supine position. Lymph fluid was drained in the following order: inguinal lymph node, thigh, around patella, popliteal lymph node, lower thigh, around ankle joint, and foot. Further, lymph was drained again in the reverse order.

Both groups received standard physical therapy on the day after surgery, which entailed bedside exercises for 20 minutes with a focus on joint range of motion (ROM) and improving muscular strength. Two days after TKA, skin and muscle mobilization were performed by the attending physiotherapist under medical supervision. In addition, ROM training, muscular and walking exercise, and stair climbing for 40 minutes once daily on weekdays were done until the day before discharge.

\section{Endpoints}

The primary endpoint was the assessment of pain intensity using the Visual Analog Scale (VAS) ${ }^{21,22)}$. Secondary endpoints including circumference of the leg, ROM of the knee joint, knee extension strength, maximum walking speed, and walking rate were measured. Measurements were made before surgery, after the removal of postsurgical drains, and after 5 days of MLD. The measurement day after 5 interventions in the control group was calculated on the assumption that 5 days were intervened on weekdays. Measurements were documented by the physiotherapist managing the recovery of patients for whom the MLD was not offered. The experience of the physical therapists in this study ranged from 4 to 30 years.

Pain while at rest, during muscle contraction while extending the knee (Quadriceps contraction), and during maximum loading (Maximum load) were evaluated using VAS. Pain at rest was measured in a sitting position about 5 minutes after entering the physiotherapy room. Pain during quadriceps muscle contraction was assumed to be pain during muscle contraction during the stance phase of walking. A $2 \mathrm{~kg}$ weight was attached to the ankle to evaluate pain when the knee was extended. Pain during maximum loading was measured in patients adopting a standing position who were directed to withstand the heaviest load possible.

Circumference of the leg was measured in $1 \mathrm{~mm}$ increments at three locations: just above the knee joint cleft, 10 $\mathrm{cm}$ in the direction of the thigh from the lateral knee joint cleft, and the maximum width of the lower thigh. Measurements immediately after surgery and after 5 MLD interventions were converted into percentages $(\%)$ of the preoperative values and used for analysis.

Joint ROM was measured in 5 degree increments using a plastic goniometer (Sakai Medical Co., Ltd.) accord- 
ing to the method of the Japan Orthopedic Surgery Society and the Japanese Rehabilitation Medicine Society. The maximum flexion and extension angle of the knee joint during active motion was also measured.

In order to measure the strength of the quadriceps, a handheld dynamometer ( $\mu$ TAS, Anima Co., Ltd.) was used $^{23)}$. In a seated posture, the patient gripped the end of the bed with both hands for truncal stabilization. The knee was flexed to 90 degrees. The dynamometer pad was positioned on the anterior aspect of the distal thigh, while the quadriceps femoris was under isometric contraction using maximal force. Three measurements were performed and the maximum value was adopted. In order to calculate the torque body weight ratio $(\mathrm{Nm} / \mathrm{kg})$, the maximum value was subsequently multiplied by the distance from the knee joint cleft to the fibula head and divided by the body weight.

Walking speed was measured according to speed during maximum effort. A $12 \mathrm{~m}$ walking path included $1 \mathrm{~m}$ before and $1 \mathrm{~m}$ after the $10 \mathrm{~m}$ section used for measurement. Based on the $10 \mathrm{~m}$ section, the first step beyond the $0 \mathrm{~m}$ and the $10 \mathrm{~m}$ line signaled the start and end of the walk test measurement, respectively. Maximum walking speed was calculated by dividing the $10 \mathrm{~m}$ distance by the walking time. Also, walking rate was calculated by dividing the number of steps by the walking time.

\section{Sample size}

To calculate the number of patients, we used the 3.1 . 2 version of PS which was freely available software. We planned for the study of continuous response variables acquired from patients in the MLD (intervention) and control groups. We based our sample size on published findings which included a report that acute pain is of significant difference clinically when VAS varies at least $13 \mathrm{~mm}$ between groups $^{24)}$. In another study of pain in the acute phase after an artificial knee joint operation, the responses within groups of patients were normally distributed with standard deviations of $15 \mathrm{~mm}^{25}$. Therefore, assuming a true difference between the MLD and control group would be represented by a mean VAS for pain of $13 \mathrm{~mm}$, we required 22 patients in each group to be able to reject the null hypothesis that the population means of the MLD and control groups are equal with a probability (power) of 0.8 . The type I error probability associated with the test of this null hypothesis is 0.05 .

\section{Randomization}

A random table was created by a research advisor at Yokohama City University. Randomization was performed using stratified block randomization. Two stratification factors were adopted, age ( $<65$ years or $\geq 65$ years) and BMI $\left(<25 \mathrm{~kg} / \mathrm{m}^{2}\right.$ or $\left.\geq 25 \mathrm{~kg} / \mathrm{m}^{2}\right)$, and for each layer defined by the combination of these levels, random assignment by the block method was used.
Patients who consented to participate in our study were not blinded in terms of their allocation to a treatment group given the obvious nature of the intervention (MLD performed immediately before physical therapy); therefore, all patients had access to information provided by the data center in our hospital rehabilitation department. The data center screened patients for their eligibility to participate in the study and allocation results were made available.

\section{Statistical methods}

Data pertaining to VAS for pain (the primary endpoint), basic attributes of patients, and the secondary endpoints were analyzed by first checking the distribution of data using the Shapiro-Wilk test. Intergroup comparisons between MLD and control groups were conducted using unpaired $t$ tests whenever normality was confirmed. In cases of nonnormally distributed data, a Mann-Whitney test was used. The level of significance was $<5 \%$ on two sided test.

Inter-group percentage differences were assessed for gender, clinical department, staging of osteoarthritis of the knee, and medication using the Chi-square test with a significance level $<5 \%$.

A two-way analysis of variance was performed to assess changes in pain between the MLD group and the control group immediately after surgery and after 5 interventions. The level of significance was $<5 \%$ on two sided test.

An analysis was performed to assess post-TKA differences in pain intensity immediately before and after MLD interventions in the MLD group using the Wilcoxon signed rank test. The level of significance was $<5 \%$ on two sided test. SPSS for Windows, Version 25.0 (SPSS Inc., Chicago, Illinois, USA) was used for this statistical analysis.

\section{Results}

The flow of patients in this study is depicted in Fig. 1. A total of 102 patients were scheduled for unilateral TKA from January to December, 2016. Among them, 52 patients were ineligible to participate based on the exclusion criteria, and 9 patients decided not to participate. Of the 41 eligible patients, 21 patients were randomly allocated to the MLD group and 20 patients were allocated to the control group. One patient in the MLD group dislocated a patella and discontinued the study before the third intervention. In addition, the hospitalization protocol was changed during the study period so that preoperative data collection became impossible, making it difficult to continue the study. Therefore, the primary endpoint of pain was assessed in 20 patients in the MLD group versus 20 patients in the control group after the fifth MLD session post TKA.

Table 1 shows the characteristics of patients, the time elapsed relevant to TKA, and the use of anti-inflammatory analgesics. The proportion of patients by severity of os- 


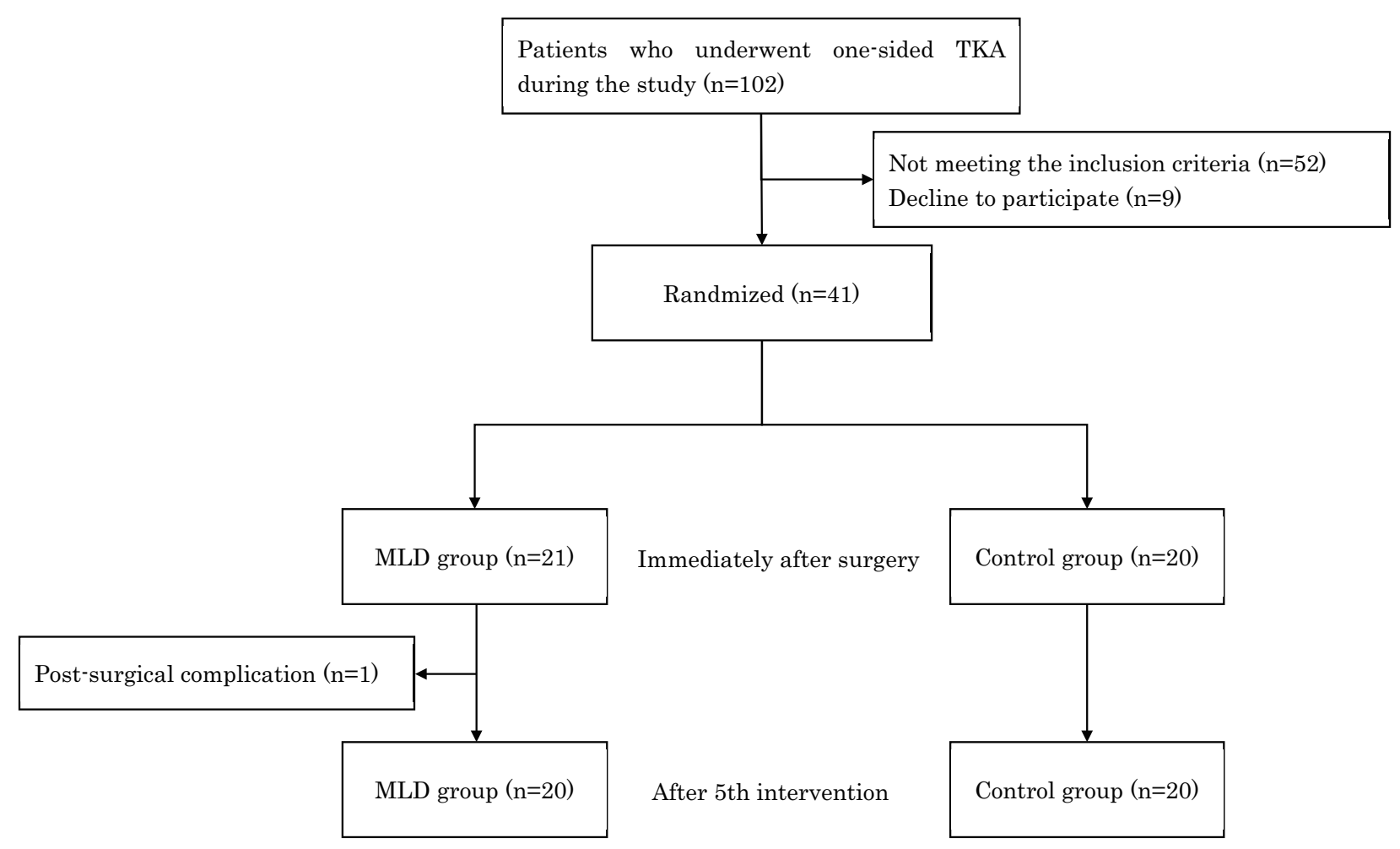

Figure 1. Flow diagram of participants recruitment process.

teoarthritis Grade (according to the Hokkaido University Stage Classification) shows significant differences among Grades. There was no significant difference between the two groups in the time elapsed immediately after the operation and in the evaluation after the 5 th intervention. For other items, no significant differences between the MLD and control groups were observed.

Results before surgery and after TKA, according to MLD interventions, are shown in Table 2. Before TKA, there was a significant difference between the groups in pain intensity during quadriceps contraction, but no significant differences between groups in pain intensity at rest or at maximum loading. However, there was no significant difference in pain intensity between groups after the final MLD intervention which represented the primary endpoint.

Table 3 shows Two-way analysis of variance results between groups and measurement times. No interaction between the groups and the measurement times was observed in pain at rest, quadriceps contraction, or pain at maximum load. Resting pain was significant in the main effects between groups and measurement times (between groups, $\mathrm{F}$ $(1,77)=5.489, \mathrm{P}=0.022$; measurement time, $\mathrm{F}(1,77)=$ $5.952, \mathrm{P}=0.017)$ ). Pain at the time of quadriceps contraction and maximum load was significant in the main effects at measurement times $(\mathrm{F}(1,77)=8.793, \mathrm{P}=0.004 ; \mathrm{F}(1$, 77) $=10.115, \mathrm{P}=0.002)$.

The immediate effect of MLD is shown in Table 4. The intensity of pain at rest before versus after MLD was significantly attenuated during interventions 1 and 3. The intensity of pain before versus after MLD during contraction of the quadriceps was significantly alleviated during the first three interventions. The number of patients was reduced after the second and fourth MLD interventions due to a patella dislocation (one patient) and because evaluations were inadvertently missed (two patients), respectively.

No serious adverse events, such as pulmonary embolism or heart failure, were observed during the study.

\section{Discussion}

The effect of MLD on acute pain was assessed before and for up to 10 days after patients in this RCT underwent a TKA in Japan. Key results warrant further discussion based on our findings.

Our data do not show that MLD interventions approximately 10 days after surgery in addition to standard physical therapy reduce pain intensity. Additionally, the secondary endpoints of the ROM, muscle strength, circumference, walking speed and walking rate did not show significant differences between the groups.

Intervention with MLD was not effective 10 days after surgery. Although the two-way analysis of variance indicated a statistically significant difference in the main effect between the groups for resting pain, we do not believe this is clinically meaningful. One reason is that there was no interaction between groups and measurement times. This in- 
Table 1. Patient characteristics, time elapsed relevant to TKA, and anti-inflammatory analgesics used*

\begin{tabular}{|c|c|c|c|c|}
\hline & $\begin{array}{l}\text { Total } \\
(\mathrm{N}=41)\end{array}$ & $\begin{array}{l}\text { MLD group } \\
\quad(n=21)\end{array}$ & $\begin{array}{l}\text { Control group } \\
\qquad(\mathrm{n}=20)\end{array}$ & $\mathrm{p}$ value \\
\hline Age (years) & $71.0(66.0-76.0)$ & $71.0(66.0-76.0)$ & $71.0(66.0-76.3)$ & $0.754 \dagger$ \\
\hline Female, n (\%) & $39(95)$ & $19(90)$ & $20(100)$ & $0.157 \S$ \\
\hline $\operatorname{BMI}\left(\mathrm{kg} / \mathrm{m}^{2}\right)$ & $26.0(4.6)$ & $25.7(4.6)$ & $26.2(4.7)$ & 0.768 \\
\hline MMSE & $29.0(26.0-30.0)$ & $29.0(27.0-30.0)$ & $28.0(26.0-30.0)$ & $0.635^{\dagger}$ \\
\hline \multicolumn{5}{|l|}{ HUSC Grade, n (\%) } \\
\hline III: Joint space reduction (1/2 or less) & 63.4 & 81.0 & 45.0 & \multirow{3}{*}{0.044} \\
\hline IV: Joint space closure & 24.4 & 9.5 & 40.0 & \\
\hline V: Loaded surface friction or subluxation & 12.2 & 9.5 & 15.0 & \\
\hline \multicolumn{5}{|l|}{ Department, n (\%) } \\
\hline Orthopedic & 78.0 & 81.0 & 75.0 & \multirow{2}{*}{$0.645 \S$} \\
\hline Rheumatology & 22.0 & 19.0 & 25.0 & \\
\hline \multicolumn{5}{|l|}{ Time elapsed (days) } \\
\hline Preoperation until TKA & $1.0(1.0-2.0)$ & $1.0(1.0-3.0)$ & $1.0(1.0-1.0)$ & $0.161^{\dagger}$ \\
\hline TKA until evaluation immediately after surgery & $4.0(2.0-4.0)$ & $3.0(2.0-4.0)$ & $4.0(2.0-4.0)$ & $0.732 \dagger$ \\
\hline TKA until end of fifth postoperative MLD & $11.0(10.0-12.0)$ & $10.5(10.0-12.0)$ & $11.0(10.8-12.0)$ & $0.300^{\dagger}$ \\
\hline \multicolumn{5}{|l|}{ Post TKA medications, $\mathrm{n}$} \\
\hline Tramadol hydrochloride orally disintegrating tablet & 7 & 3 & 4 & \multirow{6}{*}{$0.809 \S$} \\
\hline Acetaminophen & 19 & 8 & 11 & \\
\hline Loxoprofen sodium hydrate & 12 & 7 & 5 & \\
\hline $\begin{array}{l}\text { Tramadol hydrochloride/ Acetaminophen combination } \\
\text { tablet }\end{array}$ & 3 & 2 & 1 & \\
\hline Celecoxib & 12 & 6 & 6 & \\
\hline Pregabalin & 1 & 1 & 0 & \\
\hline
\end{tabular}

*Data are the mean (SD) or median (Q1-Q3) unless otherwise indicated. Mann-Whitney $U$ test. $¥$ Independent $t$-test. ${ }^{\S}$ Chi-square test. Abbreviations: BMI: body mass index, HUSC: Hokkaido University Stage Classification, MLD, manual lymph drainage, MMSE: Mini Mental State Test, Q: quartile, SD: standard deviation, TKA: total knee arthroplasty.

dicates that the rate of change was the same between groups, meaning that MLD intervention was not effective. Another reason was that the data varied widely. A previous study of MLD for TKA patients reported results spanning up to 7 days postoperatively which related primarily to swelling and $\mathrm{ROM}^{14,15)}$. The postoperative inflammatory phase peaks from 7 to 10 days after a surgical procedure. Pain during the inflammatory phase occurs when a chemical mediator binds to a nociceptor. White blood cells and plasma components involved in the generation of chemical mediators are recoverable from the lymph duct at the end of the inflammatory phase ${ }^{3-6)}$. Our study rationale was to address the importance of an intervention during this acute phase. Because patients' quality of life during the postoperative inflammatory phase following TKA is largely contingent on pain intensity, we considered our investigation of high importance. Furthermore, acute pain can reportedly also contribute to chronic pain ${ }^{26)}$. The novelty of this study pertains to our ability to evaluate the effects of MLD interventions for up to 10 days after TKA and to focus on pain intensity as the primary endpoint.

In the report of Pichonnaz et al. ${ }^{15)}$, pain intensity associated with walking on the seventh day after TKA was 33.3 $\mathrm{mm}$. In contrast, in this study, the maximum loading pain at the knee 10 days after TKA was $13.0 \mathrm{~mm}$. Ten days after surgery corresponds with the latter stage of the peak inflammatory phase. It is conceivable that the management of pain associated with medication was effective in both groups, and therefore, the effect of MLD was obscured.

Additionally, the secondary endpoints did not show significant differences between the groups. This is consistent with previous research ${ }^{14,15)}$. Swelling (inflammatory edema) is affected by obesity. When the skin is stretched due to obesity, tissue pressure is low and thus edema is likely to occur. Compared with Westerners, thinner Japanese have less edema after surgery and may be more likely to show differences due to the intervention. In fact, compared to the BMI of the subjects of the previous study, the subjects of this study showed a low average BMI of 26.0 $\mathrm{kg} / \mathrm{m}^{2}$. However, as no significant difference was shown between the groups, we conclude that the difference in physique had little influence on the results of this study.

Analysis of the immediate effects of MLD was only within the intervention group and deviates from the RCT design of this study. Therefore, it cannot be determined whether there is an immediate effect. Pichonnaz et al. com- 
Table 2. Primary and secondary endpoints at select stages of the study*

\begin{tabular}{|c|c|c|c|c|c|}
\hline & & Total & MLD group & Control group & $\mathrm{p}$-value \\
\hline \multicolumn{6}{|l|}{ Preoperative stage } \\
\hline Patients & & $\mathrm{N}=41$ & $n=21$ & $\mathrm{n}=20$ & \\
\hline \multirow[t]{3}{*}{ VAS for pain (mm) } & At rest & $4.0(0.0-16.0)$ & $3.0(0.0-5.5)$ & $9.8(0.0-26.8)$ & 0.14 \\
\hline & Quadriceps contraction & $10.0(2.0-34.0)$ & $7.0(1.5-10.5)$ & $26.5(3.0-58.5)$ & 0.014 \\
\hline & Maximum load & $19.3(2.0-32.0)$ & $11.0(1.5-26.5)$ & $25.5(7.8-32.8)$ & 0.174 \\
\hline \multirow[t]{2}{*}{$\operatorname{ROM}\left({ }^{\circ}\right)$} & Flexion & $118.2(15.8)$ & $120.5(14.4)$ & $115.8(17.3)$ & $0.35 \S$ \\
\hline & Extension & $-10.9(9.1)$ & $-10.2(9.5)$ & $-11.5(8.8)$ & $0.66^{\S}$ \\
\hline $\begin{array}{l}\text { Muscle strength } \\
(\mathrm{Nm} / \mathrm{kg})\end{array}$ & Knee extension & $0.96(0.36)$ & $0.96(0.36)$ & $0.96(0.38)$ & $0.99 \S$ \\
\hline \multirow[t]{3}{*}{ Circumference (cm) } & Knee joint cleft & $37.0(34.0-39.4)$ & $35.6(33.7-37.5)$ & $37.1(35.1-39.4)$ & $0.19 \ddagger$ \\
\hline & Thigh & $39.5(38.0-44.5)$ & $39.3(36.3-44.5)$ & $40.0(38.2-44.5)$ & 0.42 \\
\hline & Lower leg (maximum) & $35.3(32.5-36.5)$ & $35.0(32.5-36.5)$ & $35.5(32.6-36.4)$ & $0.52+$ \\
\hline $\begin{array}{l}\text { Maximum walking } \\
\text { speed }(\mathrm{km} / \mathrm{h})\end{array}$ & & $4.0(1.2)$ & $4.0(1.4)$ & $4.1(1.0)$ & $0.81 \S$ \\
\hline Walking rate (steps/s) & & $2.1(0.3)$ & $2.0(0.3)$ & $2.1(0.3)$ & $0.83 \S$ \\
\hline \multicolumn{6}{|l|}{ Immediately after surgery } \\
\hline Patients & & $\mathrm{N}=41$ & $\mathrm{n}=21$ & $\mathrm{n}=20$ & \\
\hline \multirow[t]{3}{*}{ VAS for pain (mm) } & At rest & $10.0(3.5-37.0)$ & $7.0(1.0-26.8)$ & $12.5(5.3-48.0)$ & 0.14 \\
\hline & Quadriceps contraction & $23.5(11.5-53.5)$ & $23.5(11.0-55.5)$ & $26.5(11.5-54.3)$ & 0.92 \\
\hline & Maximum load & $34.0(17.5-68.5)$ & $29.0(13.3-73.3)$ & $35.0(19.3-65.3)$ & 0.95 \\
\hline \multirow[t]{2}{*}{$\mathrm{ROM}\left(^{\circ}\right)$} & Flexion & $75.5(17.3)$ & $73.6(17.9)$ & $77.5(17.0)$ & $0.48 \S$ \\
\hline & Extension & $-15.0(-20.0$ to -10.0$)$ & $-20.0(-22.5$ to -10.0$)$ & $-15.0(-20.0$ to -10.0$)$ & 0.37 \# \\
\hline $\begin{array}{l}\text { Muscle strength } \\
(\mathrm{Nm} / \mathrm{kg})\end{array}$ & Knee extension & - & - & - & - \\
\hline \multirow[t]{3}{*}{ Circumference $(\%) \dagger$} & Knee joint cleft & $110.4(7.1)$ & $111.1(5.0)$ & $109.7(8.9)$ & $0.53 \S$ \\
\hline & Thigh & $111.3(5.9)$ & $112.8(4.9)$ & $109.8(6.6)$ & $0.11 \S$ \\
\hline & Lower leg (maximum) & $102.4(5.5)$ & $101.0(6.3)$ & $103.9(4.2)$ & $0.10 \S$ \\
\hline $\begin{array}{l}\text { Maximum walking } \\
\text { speed }(\mathrm{km} / \mathrm{h})\end{array}$ & & $2.0(0.9)$ & $1.8(1.0)$ & $2.1(0.9)$ & $0.29 \S$ \\
\hline Walking rate (steps/s) & & $1.3(0.4)$ & $1.2(0.4)$ & $1.4(0.4)$ & $0.20 \S$ \\
\hline \multicolumn{6}{|l|}{ After the fifth MLD } \\
\hline Patients & & $\mathrm{N}=40$ & $\mathrm{n}=20$ & $\mathrm{n}=20$ & \\
\hline \multirow[t]{3}{*}{ VAS for pain (mm) } & At rest & $6.5(1.6-16.5)$ & $4.5(1.6-10.8)$ & $7.0(1.8-25.5)$ & 0.17 \# \\
\hline & Quadriceps contraction & $14.5(4.5-28.8)$ & $12.3(4.5-24.8)$ & $20.8(6.4-31.8)$ & $0.41 \ddagger$ \\
\hline & Maximum load & $13.0(5.9-33.5)$ & $13.0(8.3-39.8)$ & $16.0(4.6-32.5)$ & 0.73 \\
\hline \multirow[t]{2}{*}{$\operatorname{ROM}\left(^{\circ}\right)$} & Flexion & $91.9(14.5)$ & $90.5(14.3)$ & $93.3(15.0)$ & $0.56^{\S}$ \\
\hline & Extension & $-10.0(-15.0$ to -5.0$)$ & $-10.0(-15.0$ to -5.0$)$ & $-10.0(-15.0$ to -5.0$)$ & $0.92 \ddagger$ \\
\hline $\begin{array}{l}\text { Muscle strength } \\
(\mathrm{Nm} / \mathrm{kg})\end{array}$ & Knee extension & $0.58(0.42-0.77)$ & $0.62(0.47-0.79)$ & $0.56(0.41-0.78)$ & 0.26 \\
\hline \multirow[t]{3}{*}{ Circumference $(\%) \dagger$} & Knee joint cleft & $108.0(6.5)$ & $108.9(5.6)$ & $107.1(7.3)$ & $0.38 \S$ \\
\hline & Thigh & $107.7(6.4)$ & $108.1(5.2)$ & $107.2(7.5)$ & $0.66 \S$ \\
\hline & Lower leg (maximum) & $100.0(97.6-103.1)$ & $101.6(97.7-104.0)$ & $100.0(97.2-101.9)$ & 0.40 \\
\hline $\begin{array}{l}\text { Maximum walking } \\
\text { speed }(\mathrm{km} / \mathrm{h})\end{array}$ & & $3.1(1.1)$ & $3.1(1.2)$ & $3.3(1.0)$ & $0.44 \S$ \\
\hline Walking rate (steps/s) & & $1.7(0.3)$ & $1.7(0.3)$ & $1.8(0.4)$ & $0.18^{\S}$ \\
\hline
\end{tabular}

*Data are the mean (SD) or median (Q1-Q3) unless otherwise indicated. ${ }^{*}$ Percentage of preoperative value. ${ }^{*}$ Mann-Whitney U test. sIndependent $t$-test.

Abbreviations: - : no data available, MLD: manual lymph drainage, Q: quartile, ROM: range of motion, SD: standard deviation, VAS: visual analog scale.

pared the immediate effects of hypnosis and MLD intervention groups in an RCT and reported that both groups had immediate effects with no significant differences between the groups. In this study, there was an immediate change in pain at rest for the first and third interventions and for quadriceps contraction up to the third intervention. After 
Table 3. Two-way analysis of variance results between groups and measurement times for pain*

\begin{tabular}{|c|c|c|c|c|c|c|c|}
\hline \multirow{2}{*}{$\begin{array}{c}\text { Measurement times } \\
\text { Groups }\end{array}$} & \multicolumn{2}{|c|}{ Immediately after surgery } & \multicolumn{2}{|c|}{ After the fifth MLD } & \multicolumn{2}{|c|}{ Main effect } & \multirow[t]{2}{*}{ Interaction } \\
\hline & $\begin{array}{c}\text { MLD } \\
\text { group (mm) }\end{array}$ & $\begin{array}{l}\text { Control } \\
\text { group }(\mathrm{mm})\end{array}$ & $\begin{array}{c}\text { MLD } \\
\text { group (mm) }\end{array}$ & $\begin{array}{c}\text { Control } \\
\text { group }(\mathrm{mm})\end{array}$ & $\begin{array}{l}\text { Measurement } \\
\text { times }\end{array}$ & Groups & \\
\hline Rest & $\begin{array}{c}15.1 \\
(18.4)\end{array}$ & $\begin{array}{c}24.4 \\
(24.1)\end{array}$ & $\begin{array}{c}6.1 \\
(5.4)\end{array}$ & $\begin{array}{c}14.7 \\
(15.3)\end{array}$ & $5.952 \uparrow$ & 5.489 ^ & 0.008 \\
\hline Quadriceps contraction & $\begin{array}{c}34.6 \\
(30.2)\end{array}$ & $\begin{array}{c}34.5 \\
(26.9)\end{array}$ & $\begin{array}{c}16.1 \\
(14.2)\end{array}$ & $\begin{array}{c}21.9 \\
(18.9)\end{array}$ & 8.793 ๆ ๆ & 0.290 & 0.320 \\
\hline Maximum load & $\begin{array}{c}40.0 \\
(32.1)\end{array}$ & $\begin{array}{c}38.0 \\
(24.4)\end{array}$ & $\begin{array}{c}23.8 \\
(24.3)\end{array}$ & $\begin{array}{c}18.8 \\
(16.7)\end{array}$ & 10.115 ๆ ศ & 0.391 & 0.069 \\
\hline
\end{tabular}

*Data are the mean (SD). Main effect and Interaction show F value. " $\mathrm{p}<0.05$. " $\mathrm{p}<0.01$.

Abbreviations: MLD: manual lymph drainage, SD: standard deviation.

Table 4. Immediate effect on VAS for pain before and after MLD intervention following TKA*

\begin{tabular}{|c|c|c|c|c|c|c|c|c|c|}
\hline \multirow[b]{2}{*}{$\begin{array}{l}\text { MLD inter- } \\
\text { vention, (n) }\end{array}$} & \multicolumn{3}{|c|}{$\begin{array}{l}\text { Rest } \\
(\mathrm{mm})\end{array}$} & \multicolumn{3}{|c|}{$\begin{array}{l}\text { Quadriceps contraction } \\
\qquad(\mathrm{mm})\end{array}$} & \multicolumn{3}{|c|}{$\begin{array}{l}\text { Maximum load } \\
(\mathrm{mm})\end{array}$} \\
\hline & Before & After & p-value & Before & After & $\mathrm{p}$-value & Before & After & $\mathrm{p}$-value \\
\hline First (21) & $\begin{array}{c}13.0 \\
(3.3-24.0)\end{array}$ & $\begin{array}{c}4.0 \\
(1.5-12.8)\end{array}$ & 0.015 & $\begin{array}{c}20.0 \\
(9.5-44.0)\end{array}$ & $\begin{array}{c}18.0 \\
(8.0-37.0)\end{array}$ & 0.027 & $\begin{array}{l}28.0 \\
(9.5-69.0)\end{array}$ & $\begin{array}{c}19.0 \\
(7.8-60.0)\end{array}$ & 0.217 \\
\hline Second (21) & $\begin{array}{c}6.0 \\
(2.0-133)\end{array}$ & $\begin{array}{c}3.0 \\
(1.5-11.0)\end{array}$ & 0.064 & $\begin{array}{c}17.0 \\
(9.5-44.0)\end{array}$ & $\begin{array}{c}18.0 \\
(3.3-35.5)\end{array}$ & 0.030 & $\begin{array}{c}26.0 \\
(7.5-51.5)\end{array}$ & $\begin{array}{c}20.0 \\
(8.0-47.3)\end{array}$ & 0.232 \\
\hline Third (20) & $\begin{array}{c}7.0 \\
(1.1-20.3)\end{array}$ & $\begin{array}{c}5.0 \\
(1.3-12.3)\end{array}$ & 0.032 & $\begin{array}{c}21.0 \\
(6.0-30.1)\end{array}$ & $\begin{array}{c}15.0 \\
(6.5-25.3)\end{array}$ & 0.006 & $\begin{array}{c}21.5 \\
(6.9-38.8)\end{array}$ & $\begin{array}{c}19.5 \\
(7.5-49.4)\end{array}$ & 0.203 \\
\hline Fourth (20) & $\begin{array}{c}7.0 \\
(2.0-15.3)\end{array}$ & $\begin{array}{c}5.5 \\
(1.1-10.0)\end{array}$ & 0.075 & $\begin{array}{c}11.5 \\
(5.6-28.5)\end{array}$ & $\begin{array}{c}12.8 \\
(2.0-19.8)\end{array}$ & 0.121 & $\begin{array}{c}13.5 \\
(2.6-47.8)\end{array}$ & $\begin{array}{c}9.3 \\
(2.9-31.0)\end{array}$ & 0.158 \\
\hline Fifth (18) & $\begin{array}{c}4.5 \\
(1.4-11.9)\end{array}$ & $\begin{array}{c}3.0 \\
(0.8-7.8)\end{array}$ & 0.099 & $\begin{array}{c}11.5 \\
(5.3-28.5)\end{array}$ & $\begin{array}{c}10.5 \\
(2.8-23.5)\end{array}$ & 0.308 & $\begin{array}{c}16.3 \\
(4.1-41.1)\end{array}$ & $\begin{array}{c}12.0 \\
(3.8-44.5)\end{array}$ & 0.663 \\
\hline
\end{tabular}

*Data are the median (Q1-Q3).

Abbreviations: MLD: manual lymph drainage, n: patient number, Q: quartile, TKA: total knee arthroscopy, VAS: visual analog scale.

the 4 th intervention, there were no other significant changes probably because pain was reduced and inflammatory symptoms were alleviated. There was no post-surgical change in pain at maximum load at any time point. Maximum load changed before, during, and after the intervention.

This study has several limitations. First, we could not alter the use of anti-inflammatory analgesics by patients because of ethical constraints. Therefore, there are some inherent difficulties when it comes to elucidating clinically meaningful improvements and showing significant differences between the groups assessed. Second, the method for evaluating pain was inadequate. Since VAS is a subjective evaluation, it is susceptible to the environment and to the investigator listening carefully to the subject's responses. Therefore, it is necessary to study the exact evaluation method. Third, the number of patients was smaller for each group than the scheduled sample size powered for detecting differences.

\section{Conclusion}

Our analysis showed no significant difference in pain intensity between the group that received post-TKA MLD interventions versus those in the control group that did not. In addition, the immediate effects of MLD were only investigated in the intervention group, which deviates from the RCT study design. Further study examining the immediate effects of MLD in an RCT is required.

Acknowledgments: We gratefully acknowledge the work of past and present members of Yokohama City University Medical Center and we appreciate the cooperation of all study participants.

Conflict of Interest: The authors have no conflicts of interest to disclose.

\section{References}

1) Pennington JM, Jones DP, et al.: Clinical pathways in total knee 
arthroplasty: a New Zealand experience. J Orthop Surg (Hong Kong). 2003; 11: 166-173.

2) Ayalon $\mathrm{O}$, Liu S, et al.: Multimodal clinical pathway can reduce length of stay after total knee arthroplasty. HSS J. 2011; 7: 9-15.

3) Singer AJ and Clark RA: Cutaneous wound healing. N Engl J Med. 1999; 341: 738-746.

4) Zhang JM and An J: Cytokines, inflammation and pain. Int Anesthesiol Clin. 2009; 69: 482-489.

5) Lisowska B, Maśliński W, et al.: The role of cytokines in inflammatory response after total knee arthroplasty in patients with rheumatoid arthritis. Rheumatol Int. 2008; 28: 667-671.

6) Hai-bo Si, Ti-min Yang, et al.: Correlations between inflammatory cytokines, muscle damage markers and acute postoperative pain following primary total knee arthroplasty. BMC Musculoskelet Disord. 2017; 18: 265.

7) Ranawat CS, Ranawat AS, et al.: Total knee arthroplasty rehabilitation protocol: what makes the difference? J Arthroplasty. 2003; 18: 27-30.

8) Ranawat AS and Ranawat CS: Pain management and accelerated rehabilitation for total hip and total knee arthroplasty. J Arthroplasty. 2007; 22: 295-308.

9) Vairo GL, Miller SJ, et al.: Systematic review of efficacy for manual lymphatic drainage techniques in sports medicine and rehabilitation: an evidence-based practice approach. J Man Manip Ther. 2009; 17: 80-89.

10) Eisenhart AW, Gaeta TJ, et al.: Osteopathic manipulative treatment in the emergency department for patients with acute ankle sprains. J Am Osteopath Assoc. 2003; 103: 417-421.

11) Schillinger A, Koenig D, et al.: Effect of manual lymph drainage on the course of serum levels of muscle enzymes after treadmill exercise. Am J Phys Med Rehabil. 2006; 85: 516-520.

12) Härén $K$, Backman $C$, et al.: Effect of manual lymph drainage as described by Vodder on oedema of the hand after fracture of the distal radius. A prospective clinical study. Scand J Plast Reconstr Surg Hand Surg. 2000; 34: 367-372.

13) Bakar Y, Coknaz H, et al.: Effect of manual lymph drainage on removal of blood lactate after submaximal exercise. J Phys Ther Sci. 2015; 27: 3387-3391.

14) Ebert JR, Joss B, et al.: Randomized Trial Investigating the Efficacy of Manual Lymphatic Drainage to Improve Early Outcome
After Total Knee Arthroplasty. Arch Phys Med Rehabil. 2013; 94: 2103-2111.

15) Pichonnaz C, Bassin JP, et al.: The effect of manual lymphatic drainage following total knee arthroplasty: a randomized controlled trial. Arch Phys Med Rehabil. 2016; 97: 674-682.

16) Parcells BW, Giacobbe D, et al:: Total Joint Arthroplasty in a Stand-alone Ambulatory Surgical Center: Short-term Outcomes. Orthopedics. 2016; 39: 223-228.

17) Kaneko T, Kono N, et al.: The influence of compressive forces across the patellofemoral joint on patient-reported outcome after bi-cruciate stabilized total knee arthroplasty. Bone Joint J. 2018; 100-B: 1585-1591.

18) Strössenreuther RH: Manual lymphatic drainage (MLD) according to Dr. E. Vodder. Chap 14. In: Földi M and Földi E (eds): Textbook of lymphology for physicians and lymphedema therapists. 3rd ed, Urban \& Fischer Verlag/Elsevier, GmbH, Munich, 2012, pp. 467-484.

19) Didem K, Ufuk YS, et al.: The comparison of two different physiotherapy methods in treatment of lymphedema after breast surgery. Breast Cancer Res Treat. 2005; 93: 49-54.

20) Sato K: Complex decongestive physiotherapy (CDP). Nihon Rinsho. 2005; 63: 144-153.

21) Price DD, Bush FM, et al:: A comparison of pain measurement characteristics of mechanical visual analogue and simple numerical rating scales. Pain. 1994; 56: 217-226.

22) Bijur PE, Silver W, et al.: Reliability of the visual analog scale for measurement of acute pain. Acad Emerg Med. 2008; 8 : 1153-1157.

23) Chamorro C, Armijo-Olivo S, et al.: Absolute reliability and concurrent validity of hand held dynamometry and isokinetic dynamometry in the hip, knee and ankle joint: systematic review and meta-analysis. Open Med (Wars). 2017; 12: 359-375.

24) Gallagher EJ, Liebman M, et al.: Prospective validation of clinically important changes in pain severity measured on a visual analog scale. Ann Emerg Med. 2001; 38: 633-638.

25) Nakakita $S$, Wada $O$, et al:: The site of pain and the time course of pain intensity in the acute period after total knee arthroplasty. Rigakuryoho Kagaku. 2014; 29: 917-922.

26) Kim DH, Pearson-Chauhan KM, et al.: Predictive factors for developing chronic pain after total knee arthroplasty. J Arthroplasty. 2018; 33: 3372-3378. 